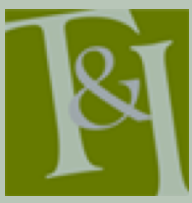

The International Journal for Translation \& Interpreting Research trans-int.org

\section{To interview or not to interview: A critical approach to assessing end-users' perceptions of the role of 21 st century indigenous interpreters in Peru ${ }^{i}$}

\author{
Raquel de Pedro Ricoy \\ Heriot-Watt University, UK \\ R.De Pedro@hw.ac.uk
}

DOI: 10.12807/ti.109201.2017.a04

\begin{abstract}
Interviews have been commonly used as a data-gathering instrument in research which approaches interpreting as a socially-situated practice (e.g. Angelelli, 2004; Inghilleri, $2006 \& 2012$ ). This paper focuses on a set of six interviews conducted with indigenous community leaders who had participated in an interpreter-mediated consultation process led by the Peruvian government in the Ucayali region between March and September of 2015. The aim is not to discuss the findings derived from the interviews themselves, but, rather, to evaluate critically the implications of adapting a well-established method for the purposes of studying the role of interpreting in a novel socio-political context.

The objective of the interviews was to garner information regarding the interviewees' perceptions of the role of the interpreters, not from a clients' perspective (the interpreters had been trained and employed by the government), but as end-users, or beneficiaries, of the interpreters' work. They were conducted in Spanish, which was the second language of all the interviewees, who had varying degrees of bilingualism. Thus, the underlying hypothesis was that they would have been able to evaluate the competence of the interpreters throughout the consultation process, which could color their perceptions as to their performance and also, potentially, their remit.

The decision was made to depart from clear-cut methodological distinctions between types of interview and adopt a hybrid approach: the questions were open-ended, but fixed, as in structured interviews; on the other hand, the possibility of seeking clarification or of prompting a follow-up (e.g. examples) to the interviewees' answers was left open, as in semi-structured interviews. An interest in how Peruvian indigenous communities construct meaning from their experience of linguistically and culturally mediated exchanges between themselves and the state underpins the choice of method. Its potential limitations is considered and measured against the benefits of tailoring research tools to the study of new realities which result from the involvement of interpreters in emerging legislated scenarios.
\end{abstract}

Keywords: End-users' perceptions, indigenous interpreters, innovative use of methods, interviews, Peru, prior consultation processes

\section{Introduction}

The aim of this paper is to assess critically the implications of adapting a wellestablished method (qualitative interviews) for the purposes of studying the

Translation \& Interpreting Vol 9 No 1 (2017) 
role of interpreting in a novel socio-political context: the legislated intercultural dialogue between the Peruvian state institutions and the indigenous peoples of the country. It focuses on the use of qualitative interviews to garner information as to the perceptions of the interpreter's role held by indigenous leaders who had participated in an interpreter-mediated prior consultation process led by the Peruvian government. Thus, its purpose is not to discuss the findings derived from the interviews themselves ${ }^{\mathrm{ii}}$, but, rather, to explore the usefulness of the chosen research tool to find answers to a specific research question: how do the representatives of the indigenous peoples of Peru understand and conceptualise the scope of the interpreter's remit in prior consultation settings?

\subsection{Background}

To contextualise the research, it is necessary to provide a brief account of the process that frames it, namely, prior consultation, and of the institutional arrangements that were put in place to enable its development in accordance with both national and international legislation.

The International Labour Organization's Indigenous and Tribal Peoples' Convention, 1989 (No. 169), of which Peru is a signatory country, aims to deliver social and economic justice for indigenous and tribal peoples. Its Article 6 states that "governments shall consult the peoples concerned, through appropriate procedures and in particular through their representative institutions, whenever consideration is being given to legislative or administrative measures which may affect them directly" (ILO, 1989). In accordance with this principle, the Prior Consultation Act ${ }^{\mathrm{iii}}$ was passed in Peru in 2011. This piece of legislation aimed to formalize the processes whereby indigenous peoples entered a dialogue with relevant State actors prior to an administrative or legislative measure that affects their rights and way of living being approved by the latter. Typically, such a measure concerns the exploitation of the country's natural resources in land inhabited by indigenous communities, which often leads to the consultations becoming emotionally charged and, sometimes, confrontational.

Crucially, the Prior Consultation Act enshrines the right of the indigenous peoples to express themselves in their own languages, of which a total of 47 exist in Peru, during the consultation. This right is not contingent on the lack of competence in Spanish, the official language of the Peruvian state, on the part of the indigenous communities concerned. In fact, it is often the case that the indigenous participants in the consultation processes, especially those who take a leading role in the dialogue with the State actors, are bilingual and, notwithstanding this, choose to use their ancestral languages rather than Spanish. As a result, the Act makes provision for State-sponsored interpreting services to facilitate communication and states that the interpreters must be trained and registered by the government body responsible for indigenous affairs. To meet this requirement, the team at the Indigenous Languages Division, which is part of the Vice-Ministry for Intercultural Affairs (itself a department of the Ministry of Culture), set up a three-week, non-language specific training program in 2012, the Basic Course ${ }^{\text {iv }}$, which has been subsequently complemented by shorter topic-specific workshops. The team also created the National Register for Indigenous Translators and Interpreters, which gained official legal status in 2016.

Thus, although since the $16^{\text {th }}$ century Peruvian indigenous people have acted as untrained, ad hoc language brokers, the role of the indigenous 
interpreter became professionalized and officially recognized for the first time in the history of the country. This role is, therefore, new to all the actors concerned (the interpreters, the State officials and the indigenous communities), as well as to society at large, and this novelty has, naturally, generated challenges that relate to the perceptions and expectations among all stakeholders. In addition, it means that little research has been conducted into the complexity of the emerging mediated interaction between the indigenous peoples and the State.

\subsection{Context: Research project and case study}

The set of interviews that is the object of the present study was conducted as part of a 20-month long (October 2014-June 2016) project entitled "Translating Cultures: the legislated mediation of indigenous rights in Peru". The project sought to address the dearth of empirical data and analysis pertaining to the new scenarios that involve translating and interpreting between Spanish and the indigenous languages of Peru in official and publicservice settings. Given its scope, a mixed-methods approach to data gathering from all relevant stakeholders (translators, interpreters, trainers, institutional representatives and indigenous people) was adopted. This provided a rich context for the development and conduct of the interviews, as well as for the analysis of the data derived therefrom and, of course, the reflection on the choice of method.

The research team (Howard, Andrade Ciudad and I) participated in the First National Encounter of Indigenous Translators and Interpreters (Lima, 2022 February 2015) and the eighth edition of the training program for indigenous translators and interpreters (Quillabamba, 17 August-5 September 2015), the abovementioned Basic Course. Our observation of these and other events, as well as the interviews that we conducted in the course thereof and subsequently, revealed that institutional representatives and trainers placed great emphasis on the neutrality of the interpreter's role and on the importance of intercultural communication. Trainees and qualified interpreters alike subscribed to both notions: they often stated that they saw themselves as a conduit for the voices of others and that being "invisible" was desirable, and they also highlighted the intercultural dimension of their role. Thus, the objective of interviewing indigenous leaders was twofold: to ascertain whether they saw the interpreter as a neutral participant in their dialogue with the State and perceived this as desirable, and to determine whether they assigned more importance to his/her role as a facilitator of the language transfer than to his/her role as a cultural broker.

The chosen prior consultation process was that of the Amazonian Waterway ("Hidrovía amazónica"), which was initiated by the Peruvian Ministry for Transport and Communications (Ministerio de Transporte y Comunicaciones, 2015). It took place in the Ucayali and Iquitos regions, in the north of Peru, between May and September 2015. The project that was the object of the consultation aimed at improving the navigability of four rivers (Amazon, Huallaga, Marañón and Ucayali), with a view to making them accessible to cargo and passenger ships so that regional, national and international trade links could be fostered.

The decision was made to interview indigenous leaders for two reasons: first, because they were guaranteed to have been active participants in the dialogue with the State in their capacity as representatives of their communities; and second, because they were expected to be bilingual (see 
section 1.1) or, at least, have knowledge of both Spanish and the indigenous language, which, in this case, was Shipibo-Conibo. The latter reason presented a practical advantage, in that I speak Spanish, but not Shipibo-Conibo; more importantly, it underlay a working hypothesis: that they would have been able to evaluate, to a greater or lesser extent, the competence of the interpreter throughout the consultation process. It was also presumed that this could colour their perceptions as to the interpreter's performance and, potentially, his remit. It must be noted that their views were sought not from a clients' perspective (since the interpreter had been trained and employed by the government), but as those of end-users, or beneficiaries, of the interpreter's work.

In this prior consultation process, the interpreter was a member of the community involved in the dialogue with the State, which gives rise to interesting questions regarding neutrality and allegiance, as well as introducing trust as a potentially determining factor in the development of the process. It is not always the case that the interpreter is an emic participant in prior consultation processes: sometimes $\mathrm{s} / \mathrm{he}$ is a speaker of the relevant indigenous language, but not a member of the community, which also has a bearing on how much trust is placed on him/her.

\section{Interviews as a research tool}

Seidman (2013, p. 8) claimed that "Interviewing [...] is a basic mode of enquiry. Recounting narratives of experience has been the major way throughout recorded history that humans have made sense of their experience." Interviews have been utilized as a data-gathering instrument in research that approaches interpreting as a socially-situated practice (e.g. Angelelli, 2004; Inghilleri, 2005; Napier, 2011) to garner information about the perceptions and expectations of the participants in interpreter-mediated exchanges: service providers, service users and, of course, interpreters. Before that, this method had been extensively used in other disciplines, such as the social and medical sciences, to obtain qualitative data. Consequently, its design and delivery, as well as its merits and its shortcomings, have been discussed by scholars who draw upon different experiences, all of which are extensible to its use within the discipline of Interpreting Studies.

Interviews can be taxonomized according to the number of participants (one-to-one conversations or focus groups), their configuration (structured, semi-structured and unstructured), and, from an epistemological perspective, their purpose (information mining or reflective interpretation). In this respect, Kvale established a distinction between the researcher as a miner and as a traveller:

in the miner metaphor, knowledge is understood as buried metal and the interviewer is a miner who unearths the valuable metal. Some miners seek objective facts to be quantified; other seek nuggets of essential meaning. In both conceptions, the knowledge is waiting in the subject's interior to be uncovered, uncontaminated by the miner. (1996, p. 3)

In contrast, according to the traveller metaphor, "The interviewer wanders along with the local inhabitants, asks questions that lead the subjects to tell their own stories of the lived world, and converses with them in the original 
Latin meaning of conversation as 'wandering together with'." (Kvale, 1996, p. 4). A further differentiation can be established in terms of how an interview is constructed: the researcher can take a leading role and design the interview by $\mathrm{him} /$ herself or adopt a collaborative approach and involve those who are culturally "on the inside" of the subject matter of the research project.

The configuration of the interview determines the pattern of interaction between the interviewer and the interviewee(s). It should be noted that, in all cases, the visibility of the former "can lead to disturbing [...] effects, when the interviewer guides with his or her behaviour the interviewee in a special direction" (Opdenakker, 2006). One-to-one interviews are normally conducted as a cogent set, whereas focus groups tend to be organised to gather information separately from different communities. Thus, the former provide a tool for contrasting data elicited from individuals who share relevant features or roles (e.g. interpreters, users, employers), whereas the latter afford the chance for such individuals to enter in a collective dialogue not only with the researcher, but also with their peers, the results of which can be then compared to those emerging from other communities. Focus groups inevitably entail group dynamics that are absent from one-to-one interviews and, consequently, the discussion takes the shape of an unstructured or a semistructured interview, as described below.

There is a wealth of literature on the intricacies of structured and semistructured interviews as qualitative research methods (for a compendium, see Atkinson \& Delamont, 2010). Structured interviews make for a strictly regulated exchange that brings to the fore the research interests for which the data are being elicited, with the general intention to favour comparability of results across participants. Semi-structured interviews revolve around a fixed set of questions or topics that can be reordered according to the flow of information and put forth in different terms, thus allowing flexibility in how the interviewees articulate their responses. Unstructured interviews can be defined as interviewee-led to an extent, in that, although it is the interviewer who initiates the dialogue, the development of his/her research agenda is steered by the interviewee's contributions.

The chosen type of interview should be closely related to its purpose. If the interviewer wants to delve into the perceptions, expectations and experiences of the interviewees, a semi-structured or an unstructured style is likely to yield richer results (see Kvale, 1996). However, if the interviewer seeks to retrieve data that will serve to answer specific research questions, a structured style is desirable. Admittedly, it can be argued that such data can be more effectively elicited by other means, such as the distribution of questionnaires, but, as will be shown below, this is not always feasible or desirable.

Following on, the purpose of the interview should determine the process for its design and its delivery. Especially in cases when interviews are designed and conducted by etic researchers, an outsider's stance may color the phrasing of the questions and the manner in which they are asked. This is not to say that rigor would be necessarily lacking, but rather, that the effectiveness of the interview as a method needs to be critically considered. Co-constructing the interview with people who have insider knowledge of the processes or the products that are being researched is a way to palliate undesired consequences; nevertheless, care should be taken that emic input does not result in a bias that distorts the potential findings. 
Regardless of their type and epistemological underpinning, it can be argued that interviews, by dint of their very nature, cannot yield findings that are as generalizable as those derived from quantitative methods, such as surveys. However, Edwards and Holland countered what they described as "ill-informed criticisms of qualitative research that have been made, for example, that it is anecdotal, illustrative, descriptive, lacks rigour, is unsystematic, biased, impossible to replicate and not generalizable" (2013, p. 91) by highlighting "good practice in understanding and undertaking qualitative interviews within the framework of a well-specified philosophical and epistemological position." (2013, p. 91). They quoted Bryman, who underscored the importance of rigorous analysis in this respect: "it is the quality of the theoretical inferences that are made out of qualitative data that is crucial to the assessment of generalization" (2001, p. 283).

\section{Application of the method}

As mentioned above, the scope of the "Translating Cultures: the legislated mediation of indigenous rights in Peru" project meant that a mixed-methods approach was adopted to gain an overview of the developing situation regarding indigenous interpreters in $21^{\text {st }}$ century Peru: a questionnaire, retrospective think-aloud protocols, one-to-one interviews, focus groups, observation, participatory research and textual analysis were used. In the case of prior consultation processes, the researchers could not observe the mediated interaction between the State agents and the indigenous communities, as access to it is restricted.

Efforts were made to procure video recordings through official channels, but they were not successful. However, the lack of this primary data did not impinge on one of the foci of interest of this part of project: how the indigenous people involved in prior consultation processes experienced communication with the State when it was conducted through an interpreter. As mentioned in section 1.2, unlike the government representatives, who are their primary interlocutors, they normally have knowledge both of Spanish (the language of the State institutions) and the indigenous language.

Face-to-face interviewing was selected as the data mining technique. The decision was made to depart from clear-cut methodological distinctions between types of interview and adopt a hybrid approach: the questions were but fixed, as in structured interviews; on the other hand, the possibility of seeking clarification or of prompting a follow-up (e.g. a request for examples or clarification) to the interviewees' answers was left open, as in semistructured interviews. The wording of the questions was agreed with a consultant who had been affiliated to the Indigenous Languages Division and, therefore, had in-depth knowledge both of the training program for translators and interpreters and of their involvement in prior consultation processes. In addition, he had some knowledge of the Shipibo language and had lived in communities in the area, on and off, for approximately two years.

The Amazonian Waterway prior consultation process was chosen as a case study for two reasons: first, because it had been recently concluded, which meant that the recall capacity of the interviewees could be expected to be good; and second, because there had been no violent clashes between government forces and the indigenous population in the area of the region where the interviews would be conducted. ${ }^{v}$ 
During the week prior to my travelling to conduct the interviews, I had been in email contact with the Shipibo interpreter who worked in the prior consultation process and asked his assistance in identifying local indigenous leaders who would be willing to be interviewed. He provided names and email addresses, but I received no responses when I contacted them. On the $27^{\text {th }}$ of September 2015, I travelled from Lima to Pucallpa (the capital city of the Ucayali region) accompanied by the abovementioned consultant. Both of us met with the interpreter, who managed to arrange the interviews by phone. All the conversations were held in Shipibo, which meant that I had no access to the exchanges. He also arranged transportation to the venues where they would be conducted (five of them in or around Pucallpa and the final one in a native community) and accompanied me and the consultant, but was not present during the interviews.

Thus, six interviews with Shipibo leaders were conducted between the $27^{\text {th }}$ and the $28^{\text {th }}$ of September 2015. All the interviewees were male and five of them had been involved in the Amazonian Waterway prior consultation process as indigenous community or organization representatives ${ }^{\mathrm{vi}}$. The consultant was present in all six and assisted with the recording equipment. The interviews were conducted in Spanish, which is my mother tongue and that of the consultant, but, as it turned out, was the second language of all the interviewees, who had varying degrees of bilingualism. After the introductions, the participants were handed an information sheet on which the project was outlined, confidentiality and anonymity were guaranteed and the names and email addresses of the three researchers involved were provided. When they gave their consent to be interviewed under those terms and to the conversation being audio- and video-recorded, they were first asked to provide their full name and, then, the following questions were put to them:

- What is your mother tongue?

- How many prior consultations have you been involved in and what was their subject matter?

- In what capacity were you involved?

- How do you perceive the participation of interpreters in prior consultation processes?

- Do you think that interpreters contribute to facilitate intercultural communication, as well as the transfer between languages?

- What do you think that the most important contribution of the interpreters in prior consultation processes should be?

As can be seen, the first three questions were closed, whereas the last three were open-ended. The interview was steered by me, but the consultant was invited to intervene on occasions when his knowledge of cultural conventions and of the processes under study was beneficial to the flow of the communication. When the interview was concluded, the participants were thanked and invited to ask any questions or make any comments that they deemed necessary. To facilitate the processing of the data, the audio recordings were subsequently sent to an agency in Lima to be transcribed.

\section{Discussion}

The decision to interview to gather reliable data to answer specific research questions, rather than to follow an exploratory approach, is, admittedly, controversial. It could be argued that the application of a method such as a 
written questionnaire would be more suitable: it would create a more controlled research environment and allow for a wider sample of the relevant population to be surveyed. The results would be more systematic, easier to process and, arguably, more generalizable. Finally, any undesirable distortions caused by interpersonal dynamics in a face-to-face situation would be avoided.

Nevertheless, this way of proceeding was discarded in this case on the evidence of a previous experience in the context of the project. In 2014, I designed an online questionnaire into which the other researchers (Howard and Andrade Ciudad) and staff from the abovementioned Indigenous Languages Division had input. Its purpose was to gain insights into the indigenous translators' and/or interpreters' profiles and to sample opinion as to their perceptions of their role and the challenges they faced. It was designed to be delivered online for the sake of reaching as wide a spectrum of respondents as possible and to eliminate the possibility of erroneous answers (e.g. choosing multiple answers when only one was required). In the end, however, it had to be distributed in hard copy to circa 100 translators and/or interpreters in the course of the First National Encounter of Indigenous Translators and Interpreters. This was due to logistical reasons, as many of the intended respondents, especially those who reside in Amazonian areas, do not have regular access to internet.

Around half of the total population that was targeted returned the questionnaire to the research team at the end of the event. Once their responses were analysed, it was found that the value of the results that it yielded, interesting though they were, was limited for what can be attributed to three main factors. First, questionnaires are a textual genre with which most of the indigenous people are unfamiliar; second, there is variation in literacy levels among them; and third, the design of the questionnaire appeared to be at odds with the discursive patterns preferred by the respondents, who often included a level of detail in their answers that had not been requested or inserted explanatory notes on the margins. ${ }^{\text {vii }}$ The confluence of these factors resulted in incorrectly entered responses, the provision of conflicting information and incomplete submissions in many cases.

Having said all that, interviewing as a method was not chosen simply by default: it presented many advantages that, it can be argued, outweighed its alleged shortcomings. Given the novel situation in Peru, a post-colonial scenario, concerning the role of indigenous interpreters as actors in the dialogue between the State institutions and the indigenous peoples of the country, an innovative application of a well-established method was necessary. An awareness of its limitations and the potential pitfalls, both during the design and conduct of the interviews and throughout the analytical process, was also essential to the rigour of the research and the validity of the results. As Edwards and Holland (2013, p. 91) argued, "It is the analysis and the cogency of the theoretical reasoning that underlies it that is the source of the generalizability of qualitative data". Let us now examine the experience of applying this method, taking into consideration the theoretical constructs mentioned above.

Indigenous Latin-American cultures are primarily oral and, therefore, interviews, even though they constitute managed dialogues as opposed to freeflowing ones, seem a more appropriate way of retrieving information than a written questionnaire. Of course, face-to-face interviews, such as the ones that are under study here, entail a gamut of interpersonal dynamics that have an 
impact on the research process and, by extension, on its product. These have often been described in terms of power differentials: for instance, Timalsina argued that, in postcolonial contexts, "the construction of cultural selves and particularly the scholar's separation of oneself from the life-events examined, has only furthered cultural misappropriation" (2014, p. 6).

When approached in the context of research into interpreting (see Rudvin, 2007), the "construction of cultural selves", in a broad sense, can be problematized in a way that differs from that which applies in other disciplines. This is because a study of interpreting is a study of the interaction between two distinct linguistic and cultural communities, as well as of the involvement of the person who makes it possible (the interpreter). Therefore, the selves that the interlocutors in the interaction and the interpreter construct weave a very complex web both when the interpreter-mediated event is taking place and when it is being recalled. This is further entangled by the involvement of the scholar, who has his/her own agenda, inevitably determined by his/her research objectives and his/her positioning regarding the object of study. Even when, as was the case with the interviews that are being discussed here, the object of study is not directly related to cultural identity, the researcher's self is unavoidably juxtaposed with that of the interviewee.

The researcher's stance, which is necessarily influenced by his/her own ideology, can interfere with how the research process is conducted, how the results thereof are analysed and how the findings are presented (see, e.g., Ratner, 2002). It can be argued that the involvement of emic researchers in projects that are developed in postcolonial contexts is not only desirable, but crucial. However, the educational opportunities that are available to the indigenous population do not always make this possible in Peru, especially in the case of Interpreting Studies, which, as a discipline, is still in its infancy in the country. Additionally, the intricacies of incorporating language-pair combinations that involve Spanish and an indigenous language are yet to be explored in a systematic manner.

I was conscious of the implications entailed by the fact that I was a female interviewing male respondents who held a high status in their communities, a stranger, an outsider, an etic researcher and a native speaker of a variety of Spanish (peninsular Castilian) that is alien to the region and associated not only with the old colonial power, but also with the current power structures ${ }^{\text {viii. }}$. Therefore, I sought to minimise any potential bias and undesired effects by involving the interpreter (male, known to the participants, an insider, an emic participant in the prior consultation process and a native speaker of Shipibo) in the preparations for the interviews. His involvement was crucial not only in facilitating access to the interviewees, but also in helping legitimize my role as a bona fide researcher. Also, the presence of the consultant (male, with a knowledge of the Shipibo language and culture, and a native speaker of Peruvian Spanish) at the interviews and his participation in them, was instrumental in dealing with communication glitches (e.g. when I used terms that were not understood or could be misinterpreted), as well as in clarifying and in enticing complementary information, given his professional knowledge of the processes under study.

Using a fixed set of questions (as in structured interviews), but allowing for follow-ups that did not depart from the topics that were central to the purpose of the interview (as in semi-structured interviews) proved to be an effective manner to garner information. The follow-ups fell into three 
categories: requests for clarification (when the answers where not specific enough), requests for examples (when general statements were made without corroboration) and requests for further information (when the participants alluded to issues tangentially related to the question but did not elaborate on them). On the one hand, this approach to interviewing resulted in a set of comparable data and, on the other, it provided nuanced insights that were derived from individual experiences.

Due to the hybridity of the methodological approach, the management of the interviews was not always straightforward. Counter to expectations, in the case of the closed questions, the participants sometimes went into narratives about their answers. More importantly in terms of research conduct, when I watched the video-recordings I realised that maintaining a clear focus for the purpose of obtaining answers to specific research questions often involved interventions on my part that reassured the respondents that their contribution was valuable through linguistic (e.g. continuity markers) or paralinguistic means (e.g. body language, such as nodding) or steered them towards clarifying, illustrating or elaborating on their statements, as alluded to above. It can be argued that this kind of intervention detracts from a detached approach to data gathering to answer specific research questions, but it was unavoidable because of the format and the context of the interviews. Nonetheless, it resulted in a richness of information that is very valuable, as it provided a level of detail that is useful to frame the analysis of the data.

This leads to a consideration of the matter of heuristics. Researchers typically have strongly held intuitions (see Marx, 1997 for a discussion of the counter-intuitive approach to formulating research questions) that determine how their methods are configured, developed and delivered (which was, admittedly, the case in how this part of the wider "Translating Cultures" research project took shape). It is, therefore, questionable whether a merely descriptive account of research results, let alone a presentation of the findings elicited from the analysis thereof, can lay any claims to objectivity; the interpretation of the data that are elicited, whether through quantitative or through qualitative means, is necessarily subjective. However, this does not mean that rigour should not be always a paramount consideration; hypotheses can be proved or disproved and researchers should be honest enough to cast aside their preconceptions when they approach the data.

Following on in relation to what the role and responsibilities of the researcher are, the distinction that has been established, metaphorically, between the researcher as either "a miner" or "a traveller" (Kvale, 1996) merits attention, given that the boundary between the two roles is not necessarily clear-cut in the conduct of qualitative research methods. As has been indicated above, I set out to conduct the interviews as "a miner", searching for nuggets of information that would enable me to find answers to the questions that, in my mind, needed to be answered for the purposes of this specific part of the project. However, I sometimes found that I was slipping into the role of "a traveller", because of the course that the discursive patterns of the interviewees took: This meant that I often felt the need to extricate myself from a dialogical exchange that, in my estimation, would distort the results gathered from the interviews and acted upon it by redirecting the conversation towards the matter at hand.

Seidman remarked that interviewing entails "an interest in understanding the lived experience of other people and the meaning they make of that experience" (2006, p. 9). An interest in how Peruvian indigenous communities 
construct meaning from their experience of linguistically and culturally mediated exchanges between themselves and the state underpinned the choice of method. ${ }^{\text {ix }}$ Interviews were chosen to fulfil the objective of gathering data related to "the lived experience" of indigenous participants in a prior consultation process that was mediated by an interpreter and, crucially, what they made of it. The conclusions derived from this process will be presented in the following section.

\section{Conclusion}

Whenever it involves human participants, a research project involves a multitude of facets whose full scope cannot be anticipated, because the consequences derived from the interplay thereof cannot be pre-empted. The experience of conducting interviews with Amazonian indigenous leaders who had lived the experience of prior consultation processes mediated through an interpreter to obtain data regarding their perceptions and expectations as to his/her role is an example of this. However, and more importantly, it rendered data that could be systematically analysed and contrasted with the research hypotheses that informed the objectives of the study.

Interviews proved to be an appropriate tool for retrieving information in the case of participants whose cultures are primarily oral. The fact that the interviews were held in the interviewees' homes or places of work allowed for observation of factors relevant to the study, therefore adding an ethnographic perspective which, as Hale and Napier (2013, p. 95) observe, is not necessarily present in all qualitative studies. The data elicited confirmed the initial hypothesis that the indigenous leaders could and, indeed, did evaluate the performance of the interpreter, by dint of them being able to understand both Spanish and Shipibo. As a consequence of that, they provided very rich insights into what they perceive as the interpreter's role in prior consultation processes.

The collaborative approach that was adopted to design and facilitate the interviews was intended to palliate a potential etic bias. As mentioned above, it tapped into the expertise of the consultant and the field experience of the interpreter. It can be argued that the involvement of the latter, who had worked in the Amazonian Waterway prior consultation process, to facilitate contact with and access to respondents introduced a bias, in that he could have selected participants who were amenable to him and were likely to praise his professional conduct. Nevertheless, from a pragmatic perspective, the interviews, which were conducted in his absence, would not have happened if he had not contacted the leaders and introduced me by phone, thereby legitimizing me as a researcher. Additionally, five of the interviewees had been key indigenous leaders involved in the process in the region. From a research point of view, furthermore, the interview questions had been phrased so that the emphasis was on the role of interpreters, rather than on the performance of a specific individual. The respondents engaged well with this approach and only one respondent referred to the interpreter by name, and did this occasionally.

The involvement of the consultant proved to be extremely useful, in that his experience of the communicative practices of the Shipibo communities, as well as his knowledge of State-led processes, had some input into the design (i.e. the phrasing of the questions) and, to an extent, the development of the 
interviews. Again, his involvement could be interpreted as an interference that could detract from the aim of this part of the "Translating Cultures" project. On the other hand, however, he had been involved as a State representative in the design and delivery of the training program for indigenous translators and interpreters, as well as being knowledgeable about prior consultation processes. As such, not only was his contribution very valuable, but also provided a counterpoint to that of the interpreter.

The fact that Spanish (which, as mentioned before was not the mother tongue of any of the interviewees, who had varying degrees of bilingualism) was the language used in the interviews had an effect in how they were conducted and in the processing of the answers that were provided: some respondents elaborated at length on the issues that were the object of the study, while one of them remarked at the end that he "had not spoken enough"; at times, follow-ups were invited and, on other occasions, redirection was needed; finally, interventions from the consultant were needed in some cases more than in others. However, a tabulation of the data based on key research items (i.e. answers to the questions that had been formulated) yielded a set of comparable results, in spite of the fact that they were differently articulated and, in two cases, they were provided at unexpected points in the course of the interview. The narrative style in which the answers were put forth meant that data processing was not a straightforward matter. That said, digressions proved to be useful. For instance, they provided a comparison of the participants' experience of the performance of untrained interpreters compared to that of interpreters who had been trained and qualified by the State, something that had not been asked.

The triangulation of methods, which can be used to corroborate or problematize research results, was possible because data had been gathered from a variety of sources (institutional representatives, translators and interpreters, trainers) throughout the "Translating Cultures" project: participatory meetings, focus groups and observation provided the most useful backdrop in this respect. I was able to compare and contrast the views expressed by the six interviewees, on the one hand, with the principles that rule the State-sponsored training of indigenous interpreters regarding the ethics of the profession and, on the other, with the trainee and qualified interpreters' perception of their role, as expressed by themselves. This comparison yielded unanticipated findings as to the alignment of the different groups' expectations with one another that would not have emerged had the interviews with the indigenous end-users not taken place.

On the issue of generalization, it can be argued that a snapshot of a specific aspect related to a prior consultation process can only afford limited inferences that are credible. However, the abovementioned triangulation of methods, which allowed the research team to draw on the experiences and opinions of government officials and interpreters from different parts of the country, suggests that the perceptions reported by the leaders whom I interviewed are widespread. This could be attributed to the fact that there are some constants when it comes to prior consultation: the process is relatively new to all the actors involved and awareness of relevant issues is not fully matured $^{\mathrm{x}}$; the format of the consultation is fixed and it always includes an intercultural dialogue between the State and the indigenous peoples that poses recurrent challenges; the same institutions are responsible for the training of all indigenous interpreters: the Indigenous Languages Division delivers the Basic Course and participates in the topic-specific workshops jointly 
facilitated by the Division for Prior Consultation and the State agencies in charge of promoting the projects; and, last but not least, most indigenous leaders are bilingual, by dint of which they can monitor the performance of the interpreter and form judgments on it.

Finally, the gathering of qualitative data provides for a comprehensive and balanced model of reporting to relevant State institutions that can be used to inform policy developments. It constitutes a richer source than that which could have been elicited through quantitative methods, such as a questionnaire. In the case of the latter, the researchers' bias in selecting and formulating specific questions would have likely resulted in a constrained set of parameters that would not have allowed for some valuable data to be collected. As mentioned above, some of the findings were unexpected and would not have been anticipated by the (etic, in this case) researcher. It seems, therefore, crucial that the researcher has an awareness of the chosen method's limitations and the potential pitfalls that may ensue when delivering it, but also, and perhaps more importantly, of its merits.

\section{Acknowledgments}

I am sincerely thankful to Rosaleen Howard (Newcastle University, UK) and Luis Andrade Ciudad (Pontificia Universidad Católica del Perú, Peru) for their guidance and support. I am also very grateful to the staff of the Indigenous Languages Division and the Prior Consultation Division of the Peruvian Ministry of Culture. Special thanks are due to Frank Janampa and Ranin Koshi, who provided great help and assistance in the stage of the Translating Cultures project that is under study here, and to the six indigenous leaders who kindly agreed to be interviewed and generously shared with me their lived experience of prior consultation mediated through an interpreter.

\section{References}

Angelelli, C. (2004). Medical interpreting and cross-cultural communication. Cambridge: Cambridge University Press.

Associated Press (2015). Three dead as Peruvian farmers and police clash at $\$ 7.4 \mathrm{bn}$ Chinese mine. Retrieved from https://www.theguardian.com/world/2015/sep/ 29/three-dead-as-peruvian-farmers-and-police-clash-at-74bn-chinese-mine

Atkinson, P. A. \& Delamont, S. (Eds.) (2010). SAGE qualitative research methods. London: SAGE Publications Ltd.

Bryman, A. (2001). Social research methods. Oxford: Oxford University Press.

Edwards, R. \& Holland, J. (2013). What is qualitative interviewing? London: Bloomsbury Academic.

Hale, S. B. and Napier, J. (2013). Research methods in interpreting: A practical resource. London: Bloomsbury.

ILO (1989): International Labour Organization's Indigenous and Tribal Peoples' Convention, 1989 (No. 169). Retrieved from http://www.ilo.org/dyn/normlex/en/ $\mathrm{f} ? \mathrm{p}=$ NORMLEXPUB:12100:0::NO::P12100_INSTRUMENT_ID:312314 
Inghilleri, M. (2005). Mediating zones of uncertainty: Interpreter agency, the interpreting habitus, and political asylum adjudication. The Translator 11(1), 6985 .

Inghilleri, M. (2012). Interpreting justice. Ethics, politics and language. London and New York: Routledge.

Kvale, S. (1996). InterViews: An introduction to qualitative research interviewing. Thousand Oaks and London: SAGE Publications Ltd.

Marx, G. T. (1997). Of methods and manners for aspiring sociologists: 37 Moral Imperatives. The American Sociologist 28(1), 102-125.

Ministerio de Transportes y Comunicaciones del Perú (2015). Consulta previa de la hidrovía amazónica. Retrieved from: http://www.mtc.gob.pe/informacion general/hidrovias/hidrovias.html

Napier, J. (2011). 'It's not what they say but the way they say it'. A content analysis of interpreter and consumer perceptions towards signed language interpreting in Australia. International Journal of the Sociology of Language 207, 59-88.

Opdenakker, R. (2006). Advantages and disadvantages of four interview techniques in qualitative research [44 paragraphs]. Forum Qualitative Sozialforschung / Forum: Qualitative Social Research,7(4), Art. 11. Retrieved from http://www.qualitative-research.net/index.php/fqs/article/view/175/391\#gcit

Peruvian Government (2011). Ley del derecho a la consulta previa a los pueblos indígenas u originarios, reconocido en el convenio 169 de la Organización Internacional del Trabajo (OIT) - Ley $\mathrm{N}^{\mathrm{o}}$ 29785. Retrieved from https://www.presidencia.gob.pe/documentos/LEY\%20DEL\%20DERECHO\%20 A $\% 20$ LA $\% 20$ CONSULTA $\% 20$ PREVIA $\% 20$ A $\% 20$ LOS $\% 20$ PUEBLOS $\% 20 I N$ D\%C3\%8DGENAS\%20U\%20ORIGINARIOS,\%20RECONOCIDO $\% 20$ EN $\% 2$ 0EL\%20CONVENIO \%20169\%20DE\%20LA\%20ORGANIZACI\%C3\%93N\%2 OINTERNACIONAL\%20DEL\%20TRABAJO\%20(OIT)\%20.pdf

Ratner, C. (2002). Subjectivity and objectivity in qualitative methodology [29 paragraphs]. Forum Qualitative Sozialforschung / Forum: Qualitative Social Research, 3(3), Art. 16. http://nbn-resolving.de/urn:nbn:de:0114-fqs0203160

Rudvin, M. (2007). Professionalism and ethics in community interpreting: The impact of individualist versus collective group identity. Interpreting 9(1), 47-69.

Seidman, I. (2013). Interviewing as qualitative research. New York: Teachers College Press.

Timalsina, S. (2014). Indigenous epistemology and placing the cultural self in crisis: A new hermeneutic model for cultural studies. Southeast Review of Asian Studies 36, 6-29.

\footnotetext{
${ }^{\mathrm{i}}$ This article is based on research conducted as part of the project entitled "Translating cultures: the legislated mediation of indigenous rights in Peru", sponsored by the UK's Arts and Humanities Research Council (award AH/M003566/1) under their Translating Cultures theme. The researchers (Rosaleen Howard, Luis Andrade Ciudad and I) gratefully acknowledge the financial support provided. For more information on the project, visit https://research.ncl.ac.uk/translatingculturesperu/

ii These are discussed in a forthcoming article by de Pedro Ricoy, Howard and Andrade Ciudad.

iii The full title of the Act is "Ley del derecho a la consulta previa a los pueblos indígenas $\mathrm{u}$ originarios, reconocido en el convenio 169 de la Organización Internacional del Trabajo (OIT) - Ley No 29785".

iv There have been nine editions of the course to date.
} 
${ }^{v}$ Cf. the situation that evolved from a concurrent prior consultation process in Las Bambas, which had been considered as a case study before it resulted in a state of emergency being declared (Associated Press 2015),

${ }^{\text {vi }}$ The sixth participant had been involved in previous processes in that capacity.

vii This provided valuable insights into a wealth of information that the respondents were keen to highlight and share.

viii Spanish has been afforded a higher status than that of the indigenous languages since the colonization of Latin-America, by dint of its being the language of the State and, until recently, the sole vehicle for formal education.

ix This interest should not be interpreted as associated with a phenomenological approach. The latter was not the focus of the research.

x An example of this is the conceptualisation of "neutrality", which, as Inghilleri observed is predicated "on the assumption of an ideal sender-receiver, context- and culture-neutral model of communication" (2012, p. 1), which cannot account for the complexities of socially and politically situated encounters. 